\title{
Caregivers of Stroke Survivors: Exploring the Role of Spousal Caregivers through an Occupational Therapy Lens
}

\author{
Lisa J. Knecht-Sabres \\ Midwestern University - Downers Grove, Iknech@midwestern.edu \\ Karley Kammer \\ Midwestern University - Downers Grove, kkammer19@midwestern.edu \\ Matthew K. Kilian \\ Midwestern University - Downers Grove, mkilian13@midwestern.edu \\ Kim Veverka \\ Midwestern University - Downers Grove, kveverka42@midwestern.edu
}

Follow this and additional works at: https://nsuworks.nova.edu/ijahsp

Part of the Occupational Therapy Commons

\section{Recommended Citation}

Knecht-Sabres LJ, Kammer K, Kilian MK, Veverka K. Caregivers of Stroke Survivors: Exploring the Role of Spousal Caregivers through an Occupational Therapy Lens. The Internet Journal of Allied Health Sciences and Practice. 2016 Jan 01;14(3), Article 4.

This Manuscript is brought to you for free and open access by the College of Health Care Sciences at NSUWorks. It has been accepted for inclusion in Internet Journal of Allied Health Sciences and Practice by an authorized editor of NSUWorks. For more information, please contact nsuworks@nova.edu. 


\title{
Caregivers of Stroke Survivors: Exploring the Role of Spousal Caregivers through an Occupational Therapy Lens
}

\begin{abstract}
The purpose of this qualitative study was to explore the occupational needs of caregivers of stroke survivors and to identify potential implications for occupational therapy's role with this population. Methods: Focus groups and a semi-structured interview were used to gather an in-depth perspective on caregivers' needs and level of participation in valued activities. Interactions were recorded and transcribed verbatim. Data analysis included open coding, formulation of categorical patterns, and thematic analysis. Rigor was enhanced through peer review, multiple coders, member checking, and triangulation. Results: Four primary themes emerged: (1) the essential need for additional services and support; (2) the amount of time spent on addressing spouses' needs resulted in occupational loss; (3) finding new ways to participate in daily life activities; and, (4) an association between the survivor's level of impairment and the caregiver's quality of life. Conclusion: Demands of caregiving can lead to changes in roles, responsibilities, and routines. OT practitioners are uniquely qualified to reinstate valued occupations into daily life, formulate balanced routines, and provide client specific supports and resources. OT services could provide strategies to enhance caregivers' ability to partake in meaningful occupations and resume a balanced lifestyle. More research is needed to determine the occupational needs of caregivers and the effectiveness of caregiver interventions.
\end{abstract}

\section{Author Bio(s)}

Lisa Jean Knecht-Sabres, DHS, OTR/L, is an Associate Professor in the Occupational Therapy Program at Midwestern University, Downers Grove, IL. Dr. Knecht-Sabres' primary areas of research have centered on adult learning, experiential learning, interprofessional education, and enhancing readiness for clinical practice. Her areas of clinical expertise have primarily focused on enhancing occupational performance for adults and older adults with physical and neurological disabilities.

Karley Kammer, MOT, earned her Master of Occupational Therapy degree at Midwestern University, Downers Grove, IL. She has OT experience with adults in acute care with orthopedic and neurological conditions; with adults with hand injuries on an out-patient basis; and, with pediatrics in the school setting.

Matthew Kilian, MOT, earned his Master of Occupational Therapy degree at Midwestern University, Downers Grove, IL. He has OT experience with adults with a plethora of conditions in acute care and in mental health.

Kimberly Veverka, MOT, earned her Master of Occupational Therapy degree at Midwestern University, Downers Grove, IL. She has OT experience with adults in in-patient rehabilitation and in pediatrics.

\section{Acknowledgements}

The researchers in this study wish to acknowledge and thank Tara Shilts and Marylee Nunley for their support and assistance. 


\title{
IJAHSP \\ The Internet Joưnal of Allied Health Sciences and Practice
}

Dedicated to allied health professional practice and education

Vol. 14 No. 3 ISSN 1540-580X

\section{Caregivers of Stroke Survivors: Exploring the Role of Spousal Caregivers through an Occupational Therapy Lens}

\author{
Lisa J. Knecht-Sabres, DHS, OTR/L \\ Karley Kammer, MOT \\ Matthew Kilian, MOT \\ Kim Veverka, MOT \\ Midwestern University \\ United States
}

\begin{abstract}
The purpose of this qualitative study was to explore the occupational needs of caregivers of stroke survivors and to identify potential implications for occupational therapy's role with this population. Methods: Focus groups and a semi-structured interview were used to gather an in-depth perspective on caregivers' needs and level of participation in valued activities. Interactions were recorded and transcribed verbatim. Data analysis included open coding, formulation of categorical patterns, and thematic analysis. Rigor was enhanced through peer review, multiple coders, member checking, and triangulation. Results: Four primary themes emerged: (1) the essential need for additional services and support; (2) the amount of time spent on addressing spouses' needs resulted in occupational loss; (3) finding new ways to participate in daily life activities; and, (4) an association between the survivor's level of impairment and the caregiver's quality of life. Conclusion: Demands of caregiving can lead to changes in roles, responsibilities, and routines. Occupational therapy practitioners are uniquely qualified to reinstate valued occupations into daily life, formulate balanced routines, and provide client specific supports and resources. Occupational therapy services could provide strategies to enhance caregivers' ability to partake in meaningful occupations and resume a balanced lifestyle. More research is needed to determine the occupational needs of caregivers and the effectiveness of caregiver interventions.
\end{abstract}

\section{Introduction}

Stroke, or cerebrovascular accident (CVA), is the leading cause of adult disability in the United States today. ${ }^{1}$ In fact, according to the Centers for Disease Control and Prevention, approximately 795,000 Americans suffer a new or recurrent stroke each year with the average length of stay being 6.1 days in an inpatient hospital following a stroke. ${ }^{1}$ With hospital length of stays decreasing and stroke prevalence rising, there has been an increase in the amount of informal care that patients are receiving following a stroke. Much of this care is provided by unpaid, informal caregivers, who are often spouses, children, and relatives of the recipient of care. ${ }^{2}$ Informal caregivers are those unpaid individuals who assist others in completing daily life activities and/or medical tasks. ${ }^{3}$ There are an estimated 65.7 million informal caregivers in the United States who are providing care for someone who is ill, disabled, or aged. ${ }^{3}$ Some conservative estimates provided from the American Heart Association assert that informal family caregivers for stroke survivors provide an average of 20.4 hours of unpaid care per week. ${ }^{2}$ Unfortunately, it appears that more studies have focused on the stroke survivors with research aimed at understanding how their lives are impacted following a stroke and less emphasis has been devoted to the informal caregivers of stroke survivors. ${ }^{4-6}$ Even though more current research has drawn attention to several noted barriers and facilitators of participation in daily life activities for stroke survivors, the needs of their informal caregivers often go unmet. . $^{-17}$ Allied health professionals are uniquely qualified to meet some of these needs. Moreover, allied health professionals, researchers, and policy makers are advocating and starting to mandate that the assessment of individuals with chronic conditions include the assessment of the family caregiver. ${ }^{18}$

More recently, strides have been taken to better understand the impact, often referred to as "burden," placed on informal caregivers. $7,10,18$, Research has suggested that the provision of informal caregiving can have negative implications on the informal 
caregivers' mental, physical, social, and financial well-being. ${ }^{10}$ Unfortunately, interventions to assist caregivers of stroke survivors have had little impact at reducing this burden. ${ }^{10,20,21}$ Employment and volunteering opportunities are greatly impacted when informal caregiving responsibilities are incorporated into a daily routine. ${ }^{14}$ Research suggests that up to $70 \%$ of informal caregivers reduce work hours, change jobs, or stop working completely to provide care for their loved one..$^{11}$ Additional research indicates that up to $83.3 \%$ of informal caregivers do not have paid jobs due to the demands of caregiving. ${ }^{16}$ Furthermore, it is estimated that family caregivers in the United States spend \$5,531 out-of-pocket annually for direct costs associated with being a caregiver which adds to the financial strain of decreased income from reduction in gainful employment. ${ }^{3}$ Moreover, informal caregivers often adjust their lives to accommodate caregiving responsibilities, and they give up things they consider to be unnecessary (e.g., regular exercise, hobbies, free time, socialization with friends, vacations, activities, and leisure time pursuits) for the betterment of the stroke survivor and family. $8,13,22$ Although informal caregivers of stroke survivors are affected in a multitude of negative ways, positive outcomes such as an increased appreciation for life, feeling needed, building strength and confidence, and feeling important and useful, have also been noted by caregivers. ${ }^{10,23,24}$ Since the need for informal caregiving following stroke is prevalent and the number of caregivers providing informal care for stroke survivors is increasing, it is important for allied health professionals to explore and address their unmet needs.

Researchers across several fields have attempted to generate knowledge surrounding the caregiver experience. Several disciplines have attempted to understand these experiences as they relate to their own scope of practice. For example, researchers in medicine have attempted to understand caregiving as it relates to physical health, highlighting morbidity and the deterioration of the caregiver's health. ${ }^{17}$ The field of psychology has identified psychiatric morbidity and strain associated with caregiving and has designed psychological interventions aimed at minimizing stress and caregiver burnout. ${ }^{12}$ Nursing professionals have used educational programs to support spouses of stroke survivors and to help these informal caregivers become competent caregivers. ${ }^{24,25}$

Healthcare professionals working in physical disability settings will see patients with a stroke more often than any other diagnosis. ${ }^{28}$ Occupational therapists are charged with addressing the needs of populations who are experiencing occupational deprivation, or an inability to participate in meaningful and satisfying life activities over a prolonged period of time. ${ }^{26,29}$ Occupations can be described as the things that people do to occupy their time and attention; they are meaningful and personal activities that individuals choose or need to engage in. ${ }^{30}$ The Occupational Therapy Practice Framework: Domain and Process, 3rd edition, identifies a broad range of occupations, including leisure, social participation, and work (both gainful employment and volunteer work). ${ }^{31}$ Multiple research studies provide evidence to support the link between occupational engagement and one's health and wellbeing. ${ }^{32}$ Investigating and better understanding the needs of caregivers for stroke survivors as they relate to everyday meaningful and relevant occupations will help identify if there truly are unmet needs, what those needs are, and how to develop foundational knowledge that can serve to guide future practice with this underserved population. Occupational therapists are distinctively qualified to develop this knowledge and work with informal caregivers so that they can live fulfilling and satisfying lives, and, ultimately, provide better care.

It has only been within the past couple of years that occupational therapy research has begun to investigate and identify occupational loss of valued activities in caregivers for stroke survivors. ${ }^{13,22}$ Informal caregivers who are unable to continue to engage in their valued activities are at risk for experiencing occupational deprivation. ${ }^{26}$ Moreover, caregivers who are challenged with balancing the role of caregiving with their other occupations may find it difficult to focus on and appreciate the positive aspects of caregiving, and as a result, are placing the recipient of care at a higher risk for negative consequences. ${ }^{27}$ In fact, preliminary evidence suggests that occupational loss is associated with lower levels of mental health among informal caregivers. ${ }^{13}$ Thus, the literature indicates a need for qualitative studies that explore losses, changes, and personal growth in caregivers of stroke survivors and recommends that future studies consider gathering information about new responsibilities and the impact of such changes. ${ }^{13}$

In summary, researchers in several fields have measured the amount of burden placed on informal caregivers of stroke survivors and have utilized several methods to describe the caregiver experience; yet, there has been little done to address the needs of these caregivers with an appreciation for their unique experiences and individual needs. Thus, there is currently a lack of in-depth knowledge to understand and address the needs of caregivers for stroke survivors as they relate to everyday meaningful and relevant occupations. The intention of this study was to explore the caregivers' needs as occupational beings; therefore, it was guided by the following research questions:

- What are the occupational needs of caregivers of stroke survivors in regards to leisure, social participation, work, and volunteer work?

(c) The Internet Journal of Allied Health Sciences and Practice, 2016 
- How can occupational therapists collaborate with caregivers to attend to their occupational needs?

\section{Methods}

To facilitate the understanding of the lived experience and occupational needs of informal caregivers providing care for a stroke survivor, a phenomenological approach was selected to guide the development of the research questions, sampling, data collection, and data analysis. ${ }^{33-35}$ This study was approved by the University's Institutional Review Board and informed consent was obtained from all participants.

\section{Participants}

A convenience sample was used to recruit all participants of this study. ${ }^{33-35}$ Only caregivers who had provided six or more months of informal care to a person who experienced a stroke were included in the study. Investigators collaborated with the head coordinator of support groups at an in-patient rehabilitation center in the Midwest to identify participants who met the inclusion criteria. Additionally, investigators recruited participants via professional networking and flyer distribution. All participants provided informed consent to partake in the study.

The participants in this study were all Caucasian and ranged from 50 to 75 years of age, with a mean age of 65 . All participants were female spousal caregivers, living in the Northwest suburbs of Chicago, IL, and were assuming the role of the primary caregiver at the time of the study.

\section{Data Collection}

This qualitative study used focus groups and individual interviews in order to gain an in-depth perspective of the experiences and needs of caregivers of stroke survivors. Three participants $(n=3)$ attended 3 consecutive focus group sessions held at a rehabilitation facility in the Midwest. Additionally, one face-to-face interview $(n=1)$ was performed at a private, yet, convenient location for the participant. Face-to-face interviews were offered to participants who met the inclusion criteria, were interested in participating in this study, but who were unable to attend the focus groups due to caregiving responsibilities or transportation issues. Focus groups and face-to-face interviews were implemented to attain personal stories and experiences related to engagement and/or inability to engage in desired leisure, social participation, work, and volunteer opportunities; strategies used to maintain occupational balance throughout their daily routine; and experiences or lack of experiences with outside caregiver supports. More specifically, the three focus groups and the individual interview were semi-structured around the guided topics and questions related to 1) leisure and social participation; 2) work and volunteer work; and 3) strategies to participate in areas of occupational performance (please see Appendix A). Use of focus groups was the preferred method of gathering qualitative data because the researchers felt that there would be value in individuals within the group being able to cue or prompt each other in ways that the researchers would not be able to do in an individual interview. ${ }^{32-34}$ The strategic composition of the focus groups promoted homogeneity by stimulating enriched discussions based on similarities of being a caregiver of a stroke survivor. Participants were also encouraged to provide differing perspectives regarding their current occupational needs in the topic areas discussed in order to highlight the importance of individualized considerations. ${ }^{35}$ However, the researchers in this study were also sensitive to the fact that there might be some informal caregivers who would be interested in participating in this study and have valuable information to share; yet, they might not be able to attend the focus groups because of caregiver responsibilities and/or transportation issues.

All focus groups and interviews were audio taped, transcribed verbatim, and lasted between 30 - 90 minutes. Please see Appendix A which provides sample focus group and interview questions. General to more specific questions were asked throughout the sessions to allow participants to open up, reflect, and consider alternatives to potentially utilize in their current routine. ${ }^{35}$ The use of both focus groups and interviews allowed for the possibility of confirming or replicating findings. ${ }^{35}$

\section{Data Analysis}

To ensure authenticity, rigor was addressed through the use of member checking, regular peer debriefing, and triangulation of data. ${ }^{33}$ Member checking was done through a follow-up interview with the participants and was used to determine the accuracy of the major themes and findings. Member checking also provided the participants with an opportunity to offer any additional thoughts. All of the participants verified the accuracy of the data; yet one out of the four of the participants $(n=1)$, after having additional time to reflect on her responses in the initial interview, offered additional information regarding her experiences of being an informal caregiver. Focus groups occurred weekly with the first three authors all being present during the data collection process. Peer debriefing, which is also sometimes referred to as analytic triangulation, occurred in two different forms. First, the three researchers who were directly involved in data collection engaged in a reflective process after each focus group and interview to discuss researcher's assumptions and identify their impact on the analysis. Additionally, these researchers used this reflective process to refine interviewing questions and techniques for future interviews. Rigor, trustworthiness and authenticity of the data was also

(C) The Internet Journal of Allied Health Sciences and Practice, 2016 
increased via peer debriefing by having the fourth author, who was not present during the active part of data collection, as well as additional peers who were not involved in this study, aid in the reflective process by probing the researchers' thinking throughout the research process (i.e., peer debriefing occurred throughout the methodology, data collection, data analysis, and interpretation of the data. ${ }^{37}$

Second, thematic analysis was used to identify patterns of behavior regarding individuals' occupational needs. $33,34,38$ Each researcher coded all of the interview transcriptions by organizing information into categorical brackets and analyzing data for patterns. ${ }^{34}$ Codes and patterns that emerged were discussed and re-coded until the first three authors came to consensus. Thematic analysis also occurred by peer review of the fourth author. Lastly, in order enhance accuracy of the data and validity of the interpreted themes, as stated above, the researchers performed member checking to ensure that the final themes portrayed the participants' insights into the occupational needs of caregivers of stroke survivors.

\section{Findings}

Four major themes emerged from the data analysis to describe the unique occupational needs of caregivers for stroke survivors. The perspectives of participants revealed similar experiences as being the primary caregiver to their spouse. Patterns of these experiences were combined together to form concise themes, which are presented next.

\section{Theme one: The Need for Additional Services and Support}

The first theme was identified as "Caregivers for stroke survivors have the essential need for additional services and support provided by healthcare professionals or community organizations." More specifically, caregivers reported the lack of availability of support groups for the caregivers of stroke survivors. They felt there was a lack of education regarding resources, which required them to find their own support networks in the community. For example, one participant reported that "there's a lot of stuff to make the caregiver a better caregiver, but not necessarily to make the caregiver's life any better." In particular, some of the participants expressed struggles to find convenient and affordable care for their husbands in order to accomplish what they wanted and needed to do throughout the day. One participant stated "I don't really want to have to pay for someone to have to come in and take care of him." Whereas, another participant asked "How do I get somebody to come in and help me if something happened to me?" Many of the participants expressed something similar to what one participant verbalized "they really don't have as much resource things out there for the caregiver." Because of the costly nature of formal caregivers, spousal caregivers were unable to pay for support, which impacted how they spent their time and decreased their ability to complete desired tasks. Caregivers identified a direct need for the provision of realistic, useful, and productive strategies to implement in daily life. In fact, one participant stated, "There were things to look at online or there was a support group at the hospital, but I found it be very unfulfilling. I don't need a coffee group." Other caregivers appreciated the social interactions as a result of participation in support groups, but found the benefits to be shortterm.

\section{Theme two: The Extensive Amount of Time Spent on Addressing Spouses' Needs Resulted in Occupational Loss}

The second theme was identified as "The abundant amount of time required to address their spouses' needs resulted in occupational loss and a need to create a balanced routine between caregiving, daily chores and household responsibilities (instrumental activities of daily living), and leisure in order to maintain optimal health and well-being." Caregivers expressed how the first few months of caregiving was solely devoted to attending to the needs of their loved ones. One participant stated that she stayed with her husband from 9am until late at night. By the time she would get home she had to help out with her grandchildren before going to bed and barely had time for anything else in her remaining schedule. "There just wasn't enough hours in a day.... it was very time consuming...I took care of him and I took care of the home...I was totally busy with my husband...there was no leisure time..." Whereas, another participant said "that initial time was mind boggling...everything got put aside...there was no time for me..." As the recovery process continued, a substantial amount of time was spent transporting their spouse to outpatient treatment sessions. Another participant explained how overwhelming the change in routine had been for her. She stated, "It's very hectic when you come over here [therapy] three times a week." She also indicated that the home exercises were a lot to handle and that she rarely had time to participate in any leisure or social activities.

Caregivers also talked about how they not only have to perform their own "household duties (e.g., laundry, cooking, cleaning, shopping), but, how they now need to perform their spouses' duties, as well (e.g., taking the garbage out, doing household repairs, paying bills). Participants described how not only caring for their spouse, but how partaking in their "husbands' jobs" also impacted their ability to do what they needed or wanted to do. One participant explained:

"My husband was the tech guru of the family, and I was happy with that arrangement, looking to him to explain or fix all issues tech. He also handled the finances and investments and his own medications, and routine doctor visits. Now I have to do those things... I joke with friends who are male caregivers whose wives have had strokes and they have

(C) The Internet Journal of Allied Health Sciences and Practice, 2016 
similar frustrations of cooking... I tell them that if they'll show me how to start the mower, I'll show them how to boil water...It's kinda funny, but it's not...now I have more work to do and less time to do some of my things....not sure who will take care of us if I get sick or injured."

Time in the caregivers' daily routine was almost solely spent attending to their spouses' rehabilitative needs. Participants shared experiences about how they would have to intentionally schedule time to do basic things like exercise or grocery shopping and had to put participating in in more "fluffy" things like leisure and social activities aside. They indicated that they were committed to their husband's recovery, which routinely appeared to supersede any of their own needs or desires, and at times, might be putting their own health and well-being at risk.

\section{Theme three: Finding New Ways to Participate in Daily Life Activities}

The third theme that was identified was centered on the concept that the caregivers suffered from occupational deprivation; yet eventually, they were able to re-engage in some meaningful and valued activities but in a modified manner. As alluded to previously, caregivers unanimously described how, especially in the beginning of the rehabilitation process, that the caregiving responsibilities were extremely demanding and left no time for leisure, social participation, or time to participate in other forms of meaningful activities. For instance, participants reported that "I can't get to church...I can't go out with friends...I can't go to the symphony...We don't do date night... We no longer go to the movies, plays, basketball games..." However, these informal caregivers discussed how they were (eventually) able to adjust and resume participation in some of their leisure and/or social activities, but in a manner which was different than how it was prior to the spouses' stroke. For example, one participant stated that "we pretty much try to go along as we did before, but maybe less often and a little slower..." Even though many of the meaningful activities in the past were lost; some were continued through modified or adapted participation. For instance, a participant described how she was part of a roller coaster club with her spouse and frequently traveled across the country to ride coasters with friends. Since her spouse could no longer participate in the riding aspect of this hobby, they began to attend "no-coaster" conventions learning about the development of parks and roller coaster structures. She said a supportive group of friends always volunteered to stay with her spouse when she had an opportunity to ride.

Planning ahead and being flexible with challenges facilitated success in resuming cherished interests together for some of the caregivers. A different couple primarily engaged in socializing with friends and family prior to the stroke as one of their major occupations. However, because of the spouse's severe language deficits after the stroke, these types of interactions came to a screeching halt. It wasn't until the couple was introduced and trained on a communication device that he was then able to effectively express his needs, and the couple was then able to actively socialize with their friends again. Ultimately, it changed how, where, and who they socialized with, but they were able to re-engage in some social opportunities in a modified manner. Another participant's primary passion had to do with reading and discussing books. She belonged to three book clubs prior to her husband's stroke. She had to let go of her preferred book club because it met in the evenings and she could not afford to pay a caregiver to stay with her husband during those hours. Recently however, she found a new book group that met in the morning, which was more conducive to her family's schedule; she wasn't able to meet with her original groups, but she was now able to participate in a leisure activity that she enjoyed. Whereas another caregiver and stroke survivor who engaged in a variety of leisure pursuits together prior to the stroke said since they are no longer able to participate in many of the events out in the community, "we now do jigsaw and word puzzles together...that's our afternoon therapy." She expressed that they can't do all of the things that they used to do, but expressed feeling very gratified that she is able to work with her husband on activities that address his physical and cognitive deficits due to his stroke and that they are now able to do something fun together again.

Theme four: An Association between the Survivor's Level of Impairment and the Caregiver's Quality of Life The final theme that was identified was that: there appears to be an association between the spouses' level of impairment after the stroke and the caregiver's overall quality of life. In other words, we discovered that the more severe the deficits were and/or the more caregiving which was required, the less likely the caregiver participated in any former occupational interests. For example, a participant explained her husband's stroke was not severe and his barriers were limited to mild limitations in the use of his right arm. She felt confident that his stroke would not create a barrier to the activities they participated in previously. More specifically, she described a brief loss of ability to engage her desired interests. The findings in this study appeared to indicate that the level of independence of the stroke survivor is associated with the psychological and/or physical stress of the caregivers. To explain further, a participant explained how she was unable to leave her husband alone because his stroke resulted in such severe limitations to his independence in daily life. She stated, "Even if he's sleeping, I cannot run out to get milk." She added that this extra stress has changed her flexibility within her routine and requires additional planning and scheduling before leaving the house. Caregivers providing care for loved ones with a lot of caregiving needs reported anxiety about burnout and limited quality of life for the caregiver and the spouse. Caregivers expressed how they were fearful about their own physical ailments and how they could combat vital caregiver responsibilities. To be more specific, one participant explained a recent experience:

(C) The Internet Journal of Allied Health Sciences and Practice, 2016 
"Well I'm having issues now where I think I tore the meniscus in my knee and it's just from lifting my husband all the time...So it's like, I'm going for an MRI Thursday...if I'm gonna be laid up, who am I gonna get to take care of him...how am I going to have to pay for that? It is all very stressful...where is the quality of life for him or me?"

In addition, another participant stated how she needs to have surgery on her foot that will require a 12-week recovery time to alleviate on-going pain. She said, "Since so much of that time I would be compromised in helping my husband, I have not figured out how to accomplish happy feet without him having huge setbacks."

\section{Discussion}

Findings of this study revealed that although each caregiver who participated in our study was unique and faced her own individual barriers, all of women expressed a fundamental need for additional services and supports tailored to caregivers, especially in terms of figuring out ways to "do it all" or ways to still be able to engage in desired leisure, social participation, and volunteer opportunities. In other words, the informal caregivers were looking for strategies to maintain an occupational balance throughout their daily routine. Moreover, those who were provided with resources in the past found them to be very unfulfilling. While personal assistants and respite care are viable options for some caregivers, services that were not reimbursed became less feasible for many caregivers because they increased the financial burden already associated with caregiving. This finding is consistent with the current literature that indicates that supports specific to caregivers' needs are largely unavailable or inept. ${ }^{7-11,14-17}$

Caregivers in this study also identified a direct need for the provision of realistic and useful strategies that would enable them to participate in valued activities, even if in a new capacity. Some researchers have shown that spouses of stroke survivors actually report lower levels of quality of life as a whole and lower satisfaction with leisure and socialization than the stroke survivors themselves. ${ }^{39}$ Kniepmann and Cupler examined occupational changes that occur in caregivers for spouses with stroke; they suggested that when a spouse and his or her caregiver are able to participate in occupations together, they then have the capacity to influence the quality of life for both the caregiver and stroke survivor. ${ }^{40}$ Likewise, the caregivers in this study expressed satisfaction and placed high value on participating in occupations with their spouses, even if they did so in a new capacity. Also, caregivers in this study believed that the survivor's impairment level following the stroke had a significant influence on their ability or inability to engage in both personal and shared occupations. These findings supported the findings in the literature which demonstrated a relationship between demands of female spousal caregivers and interference with their free time and independence. ${ }^{41}$

Caregivers who participated in this study faced different barriers and therefore would require different approaches or resources to support their engagement in valued activities. Immediately following their husband's stroke, caregivers described a selflessness and commitment to their husband's recovery that superseded any of their own needs or desires. They talked at length about how important therapy was in helping their husbands regain function and independence. Many of the women even began to take on the role of a therapist at home and were devoted to carrying out home programs. They also took on home maintenance tasks and other chores that once belonged to their husband because they did not perceive that they had any other choice, and they also felt it was their responsibility to do so. The general attitude that was common among the caregivers was, "you do what you gotta do." However, their willingness to take on so many responsibilities for the betterment of their husband and home led to occupational imbalances for these women. In other words, the results of this study reinforced the need to further explore the needs of caregivers as well as the need to address this population which appears to be at risk for occupational deprivation. 13,22,26,31

One of the biggest limitations of this study pertains to the small sample $(n=4)$ size; in other words, it is not known if the findings in this study represent the experiences of other caregivers. Although there is controversy regarding the ideal number of participants in a focus group, some researchers recommend that a focus group consist of at least 6-12 participants. ${ }^{37}$ Since the focus groups in this study only consisted of only 3 participants, it is possible that the limited number of participants in the focus groups had an impact on the information provided. Also, the researchers of this study initially sought to explore how several areas of occupation including leisure, social participation, work, and volunteering have been affected by the caregiver role. Because all of the participants were retired or only worked occasionally, the impact of caregiving on the worker role was minimally addressed. Additionally, since all of the caregivers were female spousal caregivers, this might not represent the needs and experiences of male spousal caregivers. In other words, there may be key differences if the caregiver is male, an adult child, or a friend versus a female spouse.

\section{Conclusion}

Demands of caregiving can lead to changes in roles, responsibilities, and routines. Given the large occurrence of adult disabilities as a result of strokes in the United States and the amount of people providing informal care for these stroke survivors, it is imperative to explore the occupational losses, new responsibilities, and the impact of such changes on the lives of informal caregivers. This

(C) The Internet Journal of Allied Health Sciences and Practice, 2016 
study provides preliminary evidence to suggest that there are many unmet needs of informal caregivers for stroke survivors. Occupational therapy practitioners are uniquely qualified to reinstate valued occupations into daily life, formulate balanced routines, and provide client specific supports and resources. Occupational therapy services could provide strategies to enhance caregivers' ability to partake in meaningful occupations and resume a balanced lifestyle. More research is needed to determine the occupational needs of caregivers and the effectiveness of caregiver interventions. Future studies need to include a larger sample size to better understand the impact of caregiving on the caregivers' ability to engage in meaningful occupations, how health care providers can help support the caregiver, and what the effectiveness of caregiver interventions appear to be. Future research should determine if similar findings are seen with other cohorts of female spousal caregivers as well as other types of informal caregivers.

\section{References}

1. Stroke facts: Centers for Disease Control and Prevention. Web site. http://www.cdc.gov/stroke/facts.htm_Updated March 24, 2015. Accessed May 2, 2016.

2. You're the cure. Understanding the financial costs of stroke caregiving: American Heart Association Web site. https://yourethecure.org/aha/advocacy/details.aspx?Blogld=1\&Postld=2106_Published October 25, 2013. Accessed May 2, 2016.

3. Caregiving in the U.S. 2009 in collaboration with AARP: National Alliance for Caregiving Web site. http://www.caregiving.org/data/Caregiving_in_the_US_2009_full_report.pdf Published November 2009. Accessed May 2, 2016.

4. Arbesman $M$, Lieberman $D$, Berlanstein DR. Method for the evidence-based reviews on occupational therapy and stroke. Am J Occup Ther. 2015;69(1):6901180020p1-6901180020p5. http://dx.doi.org/10.5014/ajot.2015.013524. [PMID: 25553741]

5. Hildebrand M. Effectiveness of interventions for adults with psychological or emotional impairment after stroke: An evidencebased review. Am J Occup Ther. 2015;69(1):6901180050p1-6901180050p9. http://dx.doi.org/10.5014/ajot.2015.012054. [PMID: 25553744]

6. Linder S, Rosenfeldt A, Bay R, Sahu K, Wolf S, Alberts J. Improving quality of life and depression after stroke through telerehabilitation. Am J Occup Ther. 2015;69(1):6902290020p1-6902290020p10. http://dx.doi.org/10.5014/ajot.2015.014498. [PMID: 26122686]

7. Anderson C, Linto J, Stewart-Wynne E. A Population-Based Assessment of the Impact and Burden of Caregiving for Longterm Stroke Survivors. Stroke. 1995;26:843-9. doi:10.1161/01.STR.26.5.843. [PMID: 7740578]

8. Bedini L, Estes CA. Family caregivers and leisure: An oxymoron? Parks \& Rec. 1991;37(1):25.

9. Brereton L, Carroll C, Barnston S. Interventions for adult family carers of people who have had a stroke: A systematic review. Clin Rehabil. 2007;21(10):867-84. [PMID: 17981846]

10. Cameron J, Stewart D, Streiner D, Coyte P, Cheung A. What Makes Family Caregivers Happy During the First 2 Years Post Stroke? Stroke. 2014;45:1084-9.

11. Covinsky KE, Eng C, Lui L, et al. Reduced employment in caregivers of frail elders: impact of ethnicity, patient clinical characteristics, and caregiver characteristics. J Gerontol A-Biol. 2001;56A(11):M707-13. [PMID: 11682579]

12. Draper $P$, Brocklehurst $H$. The impact of stroke on the well-being of the patient's spouse. J Clin Nurs. 2007;16:264-71. [PMID: 17239061]

13. Kniepmann, K. Female family carers for survivors of stroke: Occupational loss and quality of life. Brit J Occup Ther. 2012;75(5):208-16.

14. Ko J, Aycock D, Clark P. A comparison of working versus nonworking family caregivers of stroke survivors. J Neurosci Nurs. 2007;39(4):217-25. [PMID: 17847669]

15. Lee J, Soeken K, Picot SJ. A meta-analysis of interventions for informal stroke caregivers. Western J Nurs Res. 2007 Apr;29(3):344-56. [PMID: 17420524]

16. Oliveira AR, Rodrigues RC, De Sousa VE, et al. Clinical indicators of 'caregiver role strain' in caregivers of stroke patients. Contemp Nurs: J Australian Nurs Prof. 2013;44(2):215-24. [PMID: 23869506]

17. Van Heugten C, Visser-Meily A, Post M, Lindeman E. Care for carers of stroke patients: evidence-based clinical practice guidelines. J Clin Nurs. 2007;16(2):264-71.

18. Family Caregiver Support: Policies, Perceptions and Practices in 10 States Since Passage of the National Family Caregiver Support Program. National Alliance for Caregiving Web site:

https://caregiver.org/sites/caregiver.org/files/pdfs/op_200211_10_state_full.pdf. Published November 2002. Accessed August 1, 2015.

19. Bakas T, Clark C, Kelly-Hayes M, King R, Lutz B, Miller E. Evidence for Stroke Family Caregiver and Dyad Interventions: A Statement for Healthcare Professionals From the American Heart Association and American Stroke Association. Stroke. 2014;45:2836-52. [PMID: 25034718] 
20. Legg L, Quinn T, Mahmood F, et al. Non-pharmacological interventions for caregivers of stroke survivors. Cochrane Database Syst Rev. 2011;10:CD008179. [PMID: 21975778]

21. Visser-Meily A, Van Heugten C, Post M, Schepers V, Lindeman E. Intervention studies for caregivers of stroke survivors: a critical review. Patient Educ Couns. 2005;56:257-67. [PMID: 15721967]

22. Kniepmann K. Family caregiving for husbands with stroke: An occupational perspective on leisure in the stress process. Occup Ther J Res. 2014;34(3):131-40. [PMID: 24695365]

23. Durand M. A surprising study on caregivers. Momentum. 2011;4(2):55.

24. Moore L, Malocco G, Schmidt S, Guo L, Estes J. Perspectives of caregivers of stroke survivors: Implications for nursing. Med Surg Nurs. 2002;11:289-95. [PMID: 12520917]

25. Franzen-Dahlin A, Larson J, Murray V, Wredling R, Billing E. A randomized controlled trial evaluating the effect of a support and education programme for spouses of people affected by stroke. Clin Rehabil. 2008;22(8):722-30. [PMID: 18678572]

26. Whiteford G. Ocuupational deprivation: Global challenge in the new millennium. The Brit J Occup Ther. 2000;63:200-4.

27. Reinhard SC, Given B, Petlick NH, Bermis A. Supporting Family Caregivers in Providing Care. In Hughes RG. (Ed.). Patient Safety and Quality: An Evidence-based Handbook for Nurses. Rockville, MD: Agency for Healthcare Research and Quality (US);2008.[PMID: 21328765]

28. Woodson AM. Stroke. In Radomski M, Latham C, eds. Occupational Therapy for Physical Dysfunction, 6e. Philadelphia: Lippincott Williams \& Wilkins;2008:1001-41.

29. Rudman D. Reflections on positive aging and its implications for occupational possibilities in later life. Can J Occup Ther. 2006;73:188-92. [PMID: 16871860]

30. Boyt Schell B, Gillen G, Scaffa M. Williard \& Spackan's Occupational Therapy, 12e. Philadelphia: Wolters Kluwer/Lippincott Williams \& Wilkens; 2014.

31. American Occupational Therapy Association. Occupational therapy practice framework: Domain and process,3e. American Journal of Occupational Therapy. 2014;68:S1-48. http://dx.doi.org/10.5014/ajot.2014.682006

32. Stav WB, Hallensen T, Lane J, Arbesman M. Systematic review of occupational engagement and health outcomes among community-dwelling older adults. Am J Occup Ther. 2012;66(3):301-10. doi:10.5014/ajot.2012.003707 [PMID: 22549595]

33. Creswell J. Qualitative Inquiry \& Research Design: Choosing Among Five Approaches, 3e. Los Angeles: Sage; 2013.

34. Creswell J. Research Design: Qualitative, Quantitative, and Mixed Methods Approaches, 4e. Thousand Oaks, CA: Sage; 2014.

35. Remler D. Van Ryzin G. Research Methods in Practice: Strategies for Description and Causation, 2e. Los Angeles: Sage; 2015.

36. Gosman-Hedström G, Dahlin-Ivanoff S. Mastering an unpredictable everyday life after stroke- older women's experiences of caring and living with their partners. Scan J Caring Sci. 2012;26(3):587-97. doi:10.1111/j.1471-6712.2012.00975.x [PMID: 22332755]

37. Creswell J. Miller D. Determining validity in qualitative inquiry. TheorPract. 2000;39:124-30.

38. Saldana J. The Coding Manual for Qualitative Researchers. Thousand Oaks, CA: Sage; 2012.

39. Achten D, Visser-Meily JM, Post MW, Schepers VP. Life satisfaction of couples 3 years after stroke. Disabil Rehabil. 2012;34(17):1468-72. [PMID: 22235858]

40. Kniepmann K, Cupler M. Occupational changes in caregivers for spouses with stroke and aphasia. Brit J Occup Ther. 2014;77(1):10-8.

41. Cao V, Chung C, Ferreira A, Nelken J, Brooks D, Cott C. Changes in activities of wives caring for their husbands following stroke. Physiotherapy Canada. 2010;62:35-43. [PMID: 21197177] 